\title{
Response to Angerpointner
}

To the Editor:

I am sorry that Thomas Angerpointner perceived my review of Parting Visions (Horacek, 1998) to be harsh. My criticisms of some aspects of Melvin Morse's work should not detract from my overall, closing assessment that "this is a well-written book that articulates very nicely the vision, passion, and faith of a man who sees death-related visions as a meaningful and integral part of our lives" (p. 227). I agree with Angerpointner that Morse's book adds to our knowledge of near-death experiences and related phenomena; I disagree that my review was "a harsh dismissal" of Morse's work.

\section{Reference}

Horacek, B. (1998). [Review of Parting visions: Uses and meanings of pre-death, psychic, and spiritual experiences, by Melvin Morse, with Paul Perry]. Journal of Near-Death Studies, 16, 223-227.

Bruce J. Horacek, Ph.D. Department of Gerontology University of Nebraska at Omaha Omaha, NE 68182-0202 